\title{
Análise de conteúdo
}

\section{Marcos de referência}

Os dados
$\begin{gathered}\text { Quais são os critérios } \\ \text { de definição? } \\ \text { De qual população } \\ \text { foram extraídos? }\end{gathered}$
O objetivo
Qual é o objetivo da
análise de conteúdo?
Qual é o objetivo
das inferências?

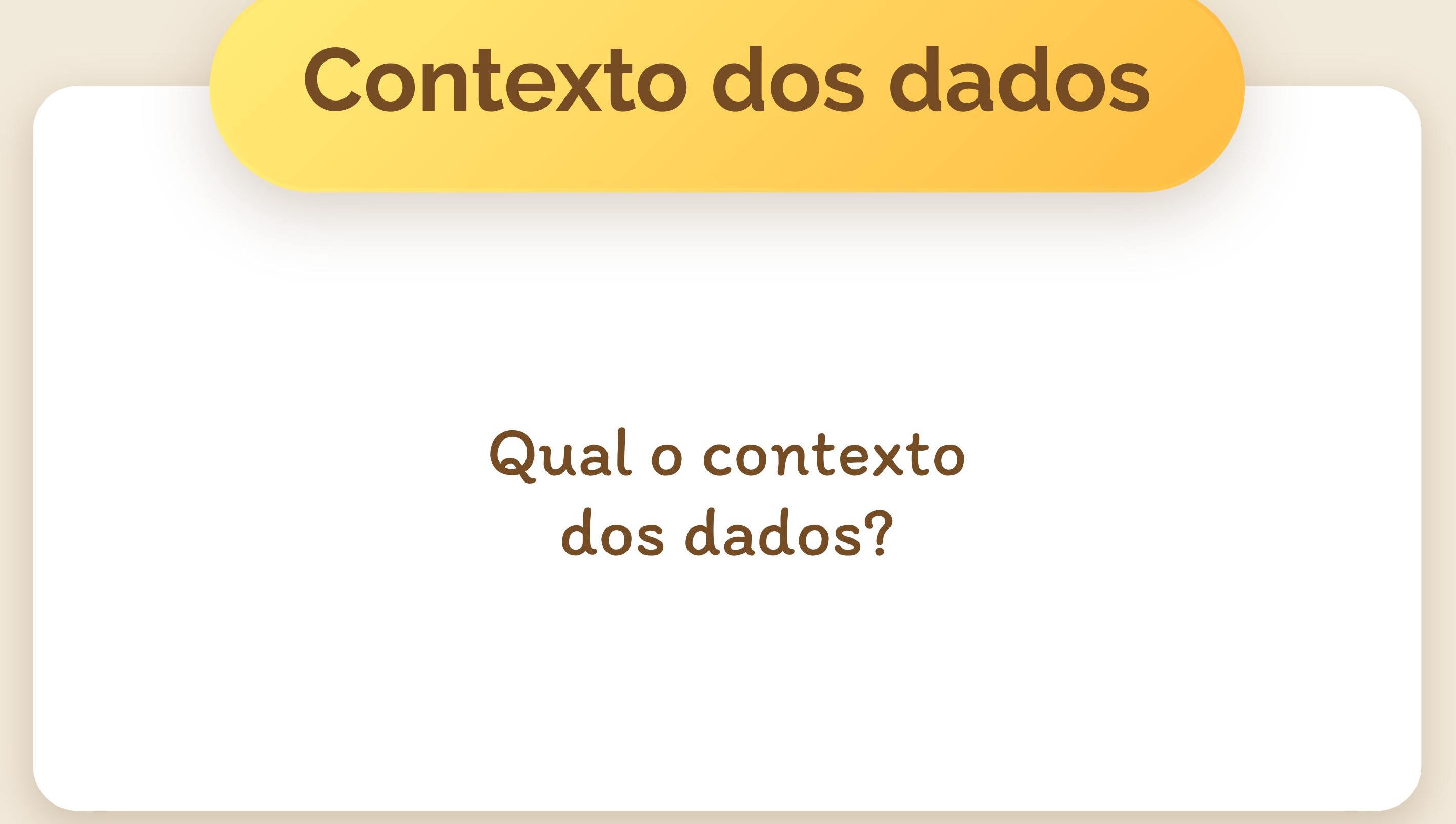

\section{O conhecimento}

do pesquisador

\section{Quais são os pressupostos das relações entre os dados e o seu contexto? \\ Isso precisa ficar claro.}

A inferência

\section{A validade}

Há relação entre os dados tidos com alguns aspectos do seu contexto?

Isso precisa ser feito.

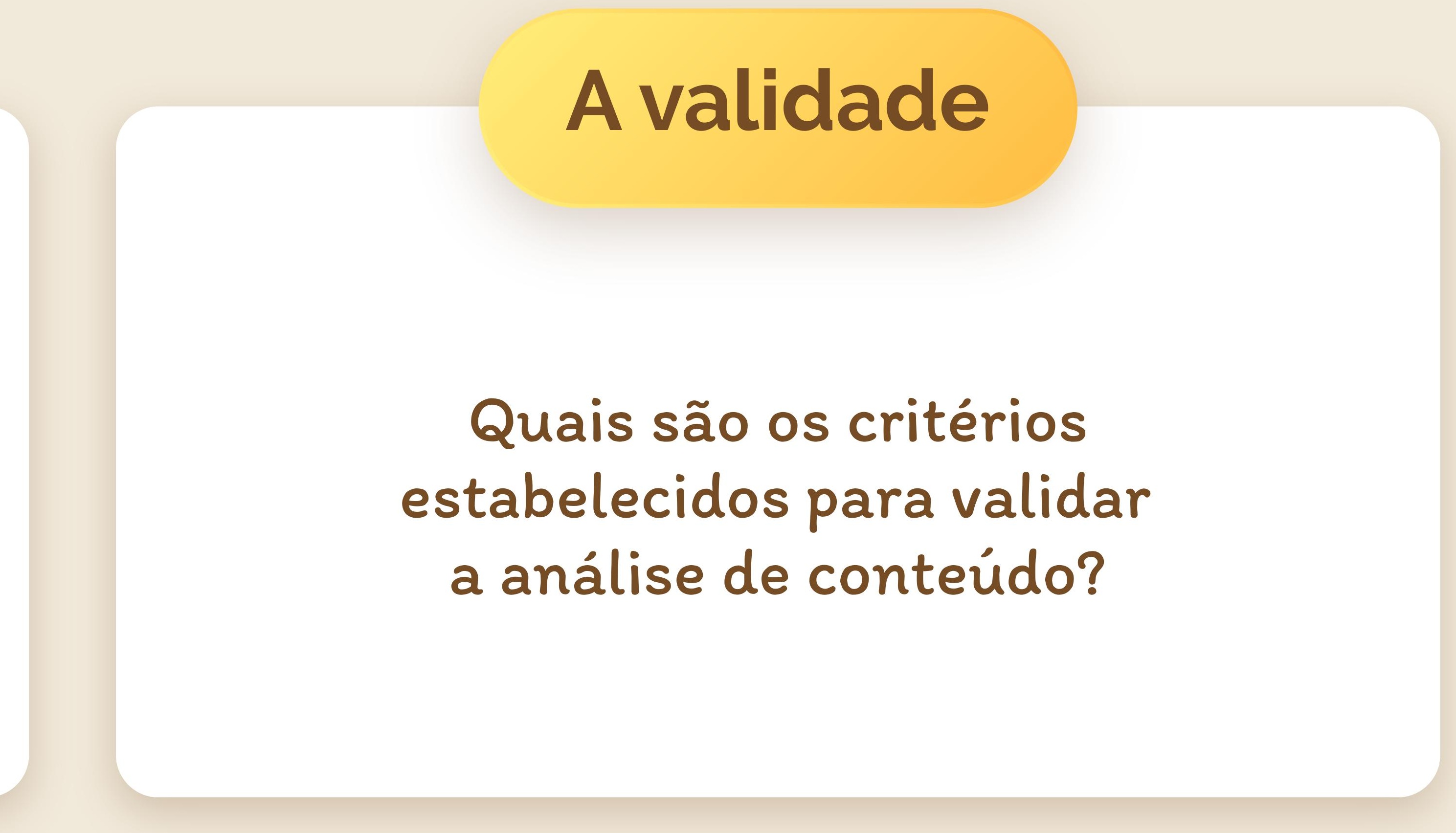

\section{0 método}

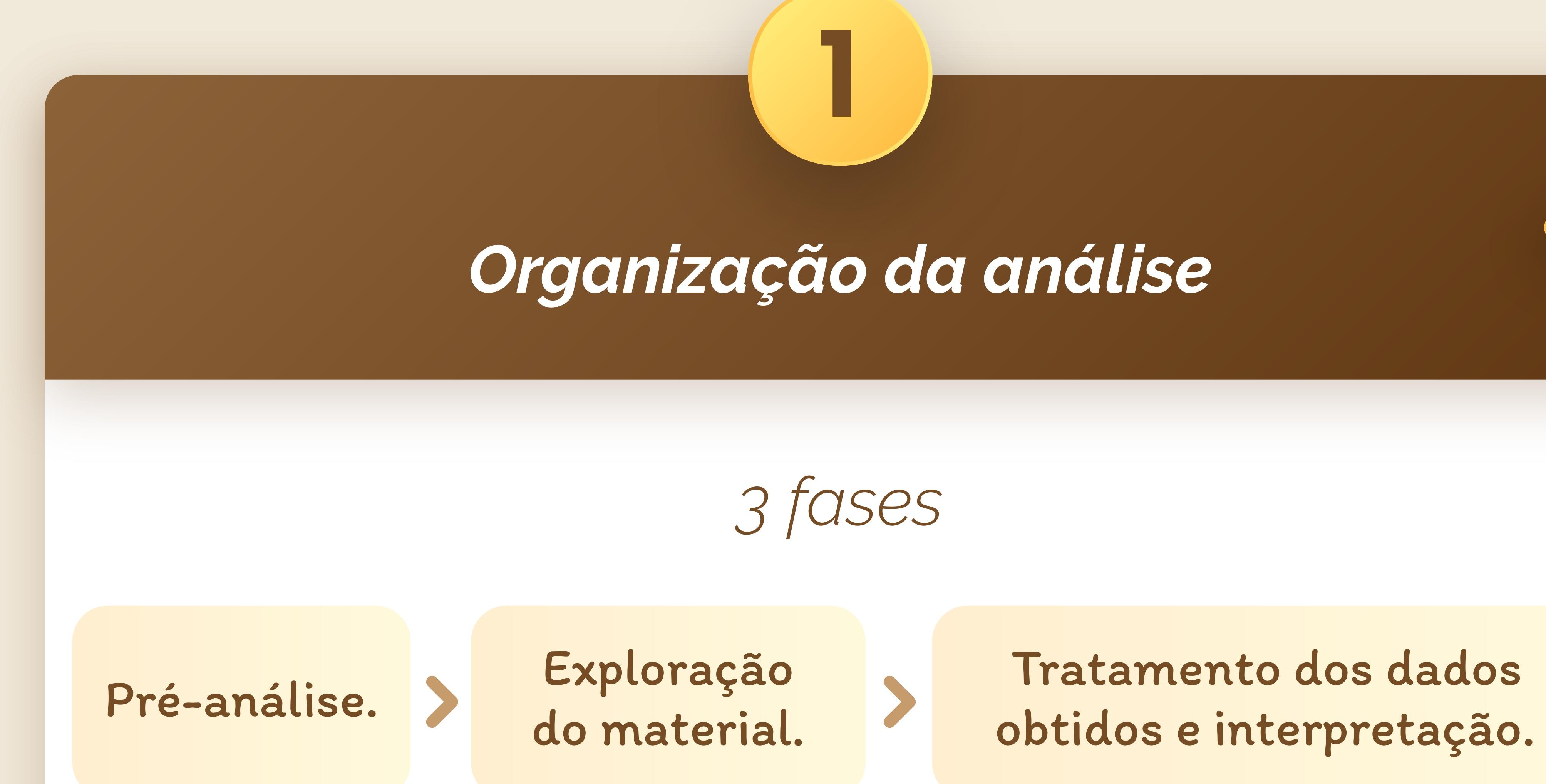

Regras de constituição do corpus

Exaustividade Representatividade

Homogeneidade Pertinência

\section{3}

Categorização

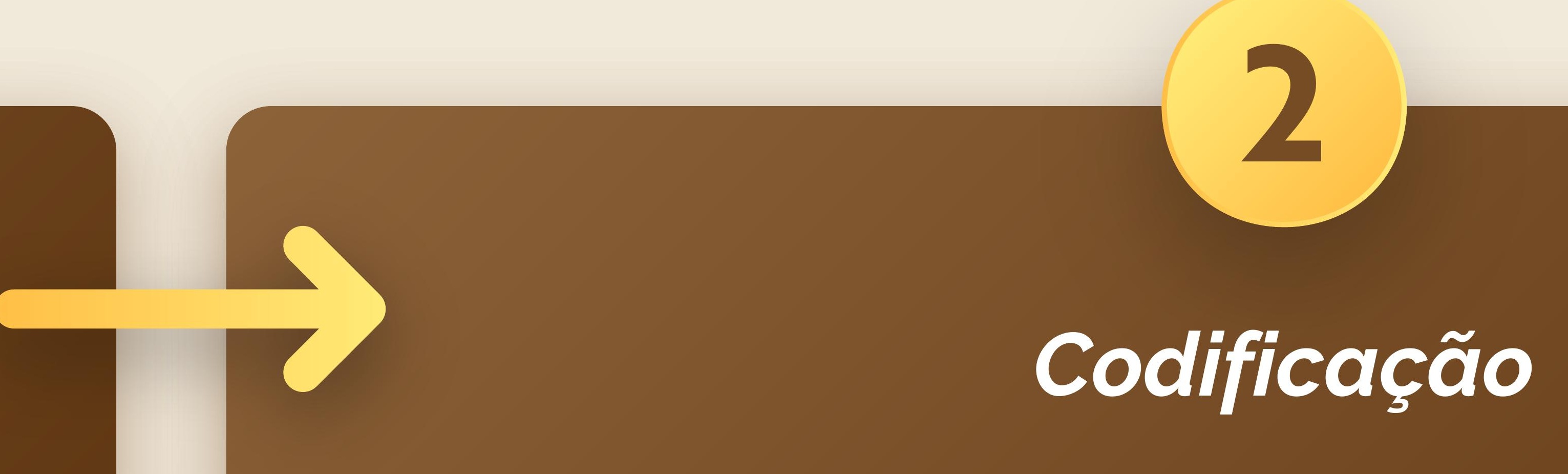

\section{3 fases}

Recorte

Escolha das unidades de registro e de contexto.

\section{$\checkmark$}

\section{Enumeração}

Modo de quantificação das unidades de registro gerando índices.

\section{$\checkmark$}

Classificação e agregação

Escolha das categorias.

Reagrupamento das unidades de registro em número reduzido de categorias.

Critérios

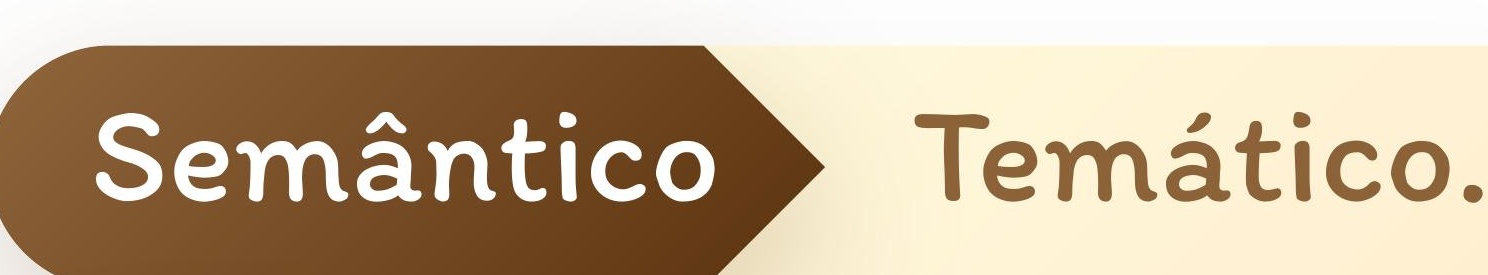

Sintático Verbos, adjetivos.

Léxico Sentido.

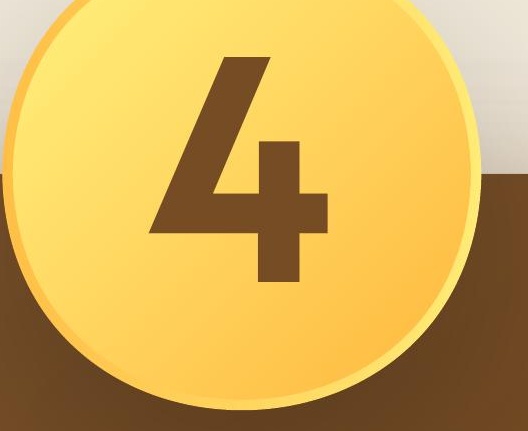

Inferência

Condições de produção das mensagens analisadas.

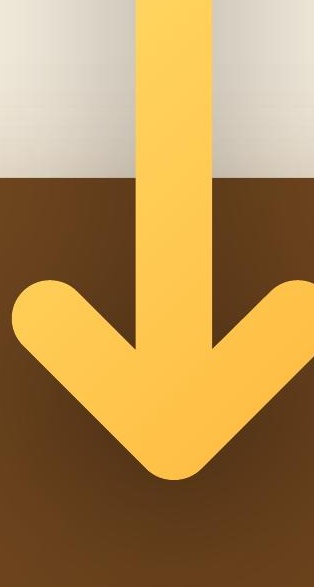

Tratamento informático
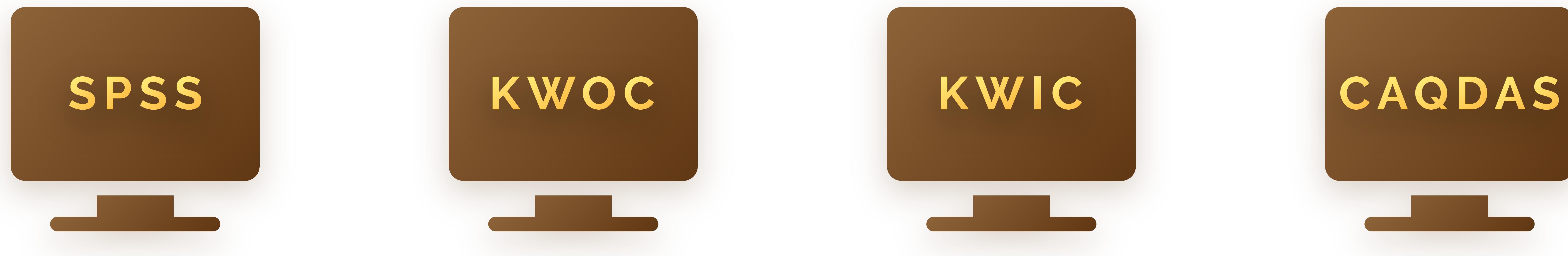

Keyword Out of Contex

Keywords in Context

Computer-Assisted Qualitative Data Analysis Software 